\title{
Vibration Control of Nuclear Power Plant Piping System Using Stockbridge Damper under Earthquakes
}

\author{
Seongkyu Chang, ${ }^{1}$ Weipeng Sun, ${ }^{2}$ Sung Gook Cho, ${ }^{3}$ and Dookie Kim ${ }^{4}$ \\ ${ }^{1}$ Academic-Industry Cooperation Foundation, Kunsan National University, Jeonbuk, Republic of Korea \\ ${ }^{2}$ Department of Mechanics and Engineering Science, School of Mathematics, Jilin University, Changchun 130012, China \\ ${ }^{3}$ ReD Center, Innose Tech Co. Ltd., Incheon 406-840, Republic of Korea \\ ${ }^{4}$ Department of Civil Engineering, Kunsan National University, Jeonbuk, Republic of Korea
}

Correspondence should be addressed to Seongkyu Chang; s9752033@gmail.com

Received 6 September 2016; Accepted 3 November 2016

Academic Editor: Eugenijus Ušpuras

Copyright (C) 2016 Seongkyu Chang et al. This is an open access article distributed under the Creative Commons Attribution License, which permits unrestricted use, distribution, and reproduction in any medium, provided the original work is properly cited.

\begin{abstract}
Generally the piping system of a nuclear power plant (NPP) has to be designed for normal loads such as dead weight, internal pressure, temperature, and accidental loads such as earthquake. In the proposed paper, effect of Stockbridge damper to mitigate the response of piping system of NPP subjected to earthquake is studied. Finite element analysis of piping system with and without Stockbridge damper using commercial software SAP2000 is performed. Vertical and horizontal components of earthquakes such as El Centro, California, and Northridge are used in the piping analysis. A sine sweep wave is also used to investigate the control effects on the piping system under wide frequency range. It is found that the proposed Stockbridge damper can reduce the seismic response of piping system subjected to earthquake loading.
\end{abstract}

\section{Introduction}

Usually nuclear power plant (NPP) piping system needs to be designed for various loads such as dead weight, internal pressure, temperature, and accidental loads as well as for seismic loads. These loads can occur inside the nuclear power plant piping system and affect the operation of the plant. Researchers have investigated ways to reduce pipe vibration using various devices, including snubbers, pipe hangers, support systems, and isolators. Kunieda et al. [1] proposed three control devices for piping systems to increase the damping ratio: a direct damper, vibration absorber, and connecting damper. Olson and Tang [2] proposed snubber and seismic stops to suppress the vibration of a nuclear power plant piping system; however, it is very difficult to frequently inspect snubbers in the high-radiation conditions in a nuclear power plant, and the cost for installation was prohibitively expensive. Shimuzu et al. [3] developed a seismic response analysis procedure of the piping system and performed an evaluation of the piping response by comparing simulated results and tested results. Park et al. [4] performed the shaking table test and simulation for the main steam and feedwater lines with conventional snubbers and energy absorbing supports. Parulekar et al. [5] performed analytical and experimental research to reduce the vibration of the piping and equipment of a nuclear power plant using elastoplastic dampers (EPD). Abe et al. [6] conducted the seismic proving test of Lead Extrusion Damper (LED) and developed the characteristic evaluation formula for LED. Moreover, Fujita et al. [7] proposed a method of nonlinear seismic response analysis for a piping system using a combination of the Finite Element Method (FEM) and the Differential Algebraic Equations (DAE). Bakre et al. [8] inspected the effectiveness of sliding friction dampers for piping systems using analytical and experimental methods. Bakre et al. [9] attempted to optimize x-plate dampers and the seismic effectiveness of these dampers for a piping system in industrial installations.

In this study, a Stockbridge damper (SBD), originally developed by Stockbridge in 1925 [10], is suggested to suppress the vibration of a nuclear power plant piping system under earthquakes. Wagner et al. [11] established a theoretical analysis of the response characteristics of SBD to verify 


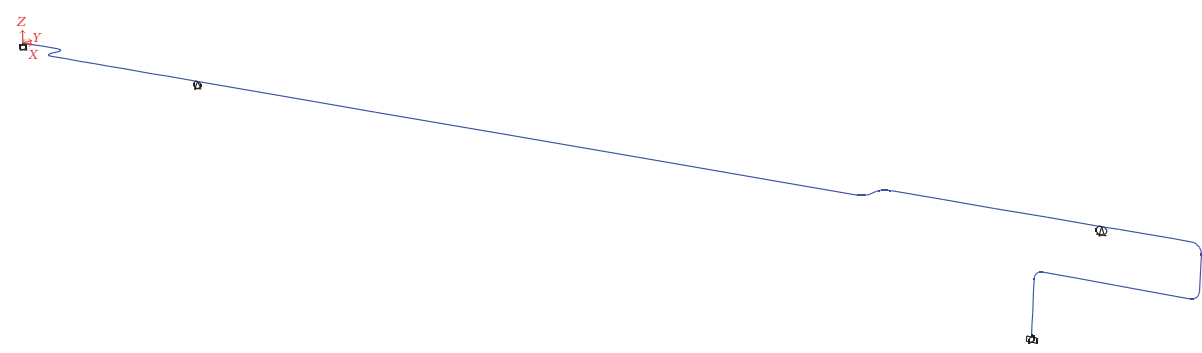

(a) $3 \mathrm{D}$ view

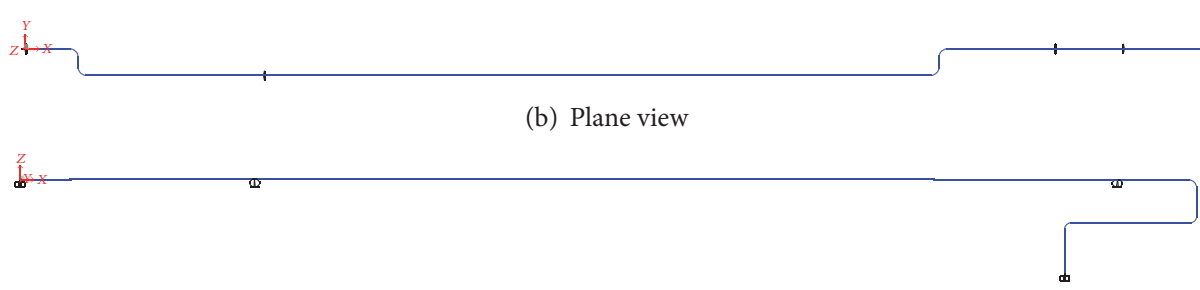

(c) Elevation view

FIGURE 1: Nuclear power plant piping system for earthquake analysis.

a theoretical predictions experimental test. The SBD was used to reduce the vibration of slender structures in wind, such as overhead transmission lines and stayed cables [12-15]. Vecchiarelli et al. [12] performed numerical analysis to predict the vertical, steady-state, aeolian vibration of a single conductor span attached with a Stockbridge-type damper. Thereafter, Barry [13] developed a finite element model to evaluate the vibrational response of a single conductor with a Stockbridge damper and investigate the effects of the Stockbridge damper. Urushadze et al. [14] conducted experimental and numerical verification of wind-induced vibration of hangers on the pedestrian bridge and suggested to equip the hangers with Stockbridge dampers. To investigate the linear and nonlinear dynamic behavior of asymmetric Stockbridge damper, an experimental test and a numerical analysis were performed by N. Barbieri and R. Barbieri [15].

In this study, a piping system (ASCE CLASS1 SA312 GRADE TP316 SCH) was installed in identical conditions to those in a real nuclear power plant and was used to investigate the control performance of the SBD. Finite element analysis of piping system with and without Stockbridge damper was performed using commercial software SAP2000. A sine sweep wave was used to investigate the control effects on the piping system under wide frequency range. In order to confirm the control effects of the Stockbridge damper under random earthquake vibration, the three selective (El Centro, California, and Northridge) earthquakes were used in this investigation.

\section{Piping System}

2.1. Outline of Piping System. The nuclear power plant piping system was composed of 2- and 3-inch sized pipes; the length of the axis of ordinates is $17.8 \mathrm{~m}$; the end of the pipe tip was fixed; and 2 reducers were modeled as hinge conditions. It is assumed that the inner space of the pipe was filled with water. The water was modeled as an additional mass.
TABLE 1: Material properties.

\begin{tabular}{lcc}
\hline Item & Value & Unit \\
\hline Young's modulus & 199,000 & $\mathrm{MPa}$ \\
Poisson's ratio & 0.31 & - \\
Steel density & 7,850 & $\mathrm{~kg} / \mathrm{m}^{3}$ \\
Water density & 1,000 & $\mathrm{~kg} / \mathrm{m}^{3}$ \\
\hline
\end{tabular}

TABLE 2: Section properties.

\begin{tabular}{lccc}
\hline $\begin{array}{l}\text { Pipe size } \\
\text { (in) }\end{array}$ & $\begin{array}{c}\text { External diameter } \\
(\mathrm{mm})\end{array}$ & $\begin{array}{c}\text { Internal diameter } \\
(\mathrm{mm})\end{array}$ & $\begin{array}{c}\text { Thickness } \\
(\mathrm{mm})\end{array}$ \\
\hline 2 & 60.3 & 42.8 & 8.74 \\
3 & 88.9 & 66.6 & 11.13 \\
\hline
\end{tabular}

Figure 1 shows the piping system modeled by SAP2000. The material properties and cross-sectional properties of the pipe are shown in Tables 1 and 2. All properties were applied as the values suggested by the design criteria.

2.2. Free Vibration Analysis. A free vibration analysis was performed with respect to the piping system in order to calculate the parameters of the damper such as mass, frequency ratio, and damping ratio. From the free vibration analysis, the first to third modes show very complex modal shapes which are a combination of horizontal and vertical shapes as shown in Figures 2-4. The first and third mode shapes are predominantly horizontal mode shaped, and the second mode shape is predominantly vertical mode shaped. The maximum amplitudes of where the damping device will be installed were marked using a red color dot. The dynamic properties of the piping system calculated from free vibration analysis results are shown in Table 3.

Since the main control target modes are the first to third modes, each generalized mass was calculated up to the third mode. 
TABLE 3: Dynamic properties of the piping system.

\begin{tabular}{|c|c|c|c|c|c|c|}
\hline \multirow{2}{*}{ Mode } & \multirow{2}{*}{ Period (sec) } & \multirow{2}{*}{ Frequency $(\mathrm{Hz})$} & \multicolumn{3}{|c|}{ Modal participating mass ratio } & \multirow{2}{*}{ Generalized mass $(\mathrm{kg})$} \\
\hline & & & $x$ & $y$ & $z$ & \\
\hline 1 st & 0.575 & 1.741 & 0.0003 & 0.3800 & 0.0642 & 182 \\
\hline 2nd & 0.471 & 2.125 & 0.0000 & 0.0641 & 0.4100 & 170 \\
\hline $3 r d$ & 0.190 & 5.254 & 0.0020 & 0.0185 & 0.0002 & 166 \\
\hline 4 th & 0.173 & 5.779 & 0.0007 & 0.0001 & 0.0005 & - \\
\hline 5 th & 0.102 & 9.806 & 0.0280 & 0.0091 & 0.0000 & - \\
\hline 6 th & 0.086 & 11.563 & 0.0000 & 0.0003 & 0.0183 & - \\
\hline 7 th & 0.074 & 13.426 & 0.0128 & 0.1200 & 0.0004 & - \\
\hline 8 th & 0.059 & 16.869 & 0.3000 & 0.0096 & 0.0211 & - \\
\hline
\end{tabular}

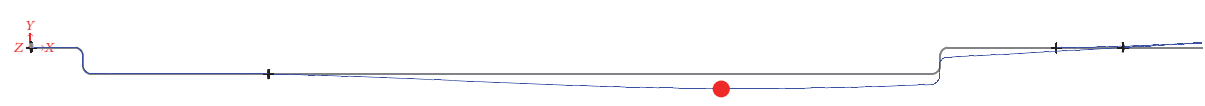

(a) Plane view

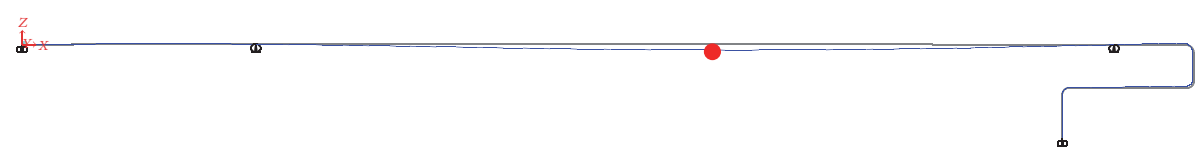

(b) Elevation view

FIGURE 2: First mode shape.

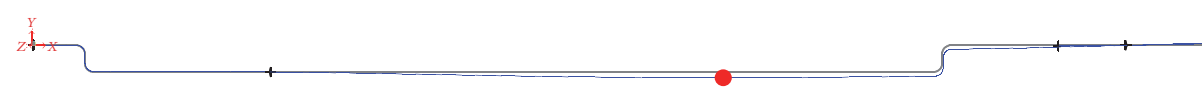

(a) Plane view

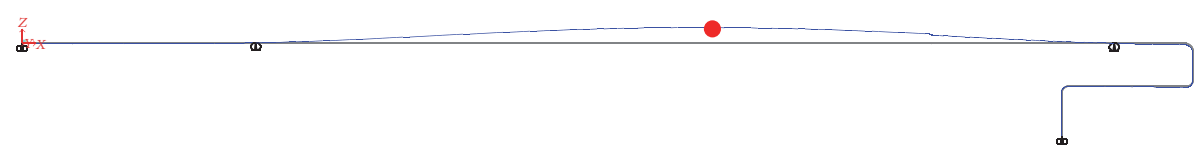

(b) Elevation view

FIgURE 3: Second mode shape.

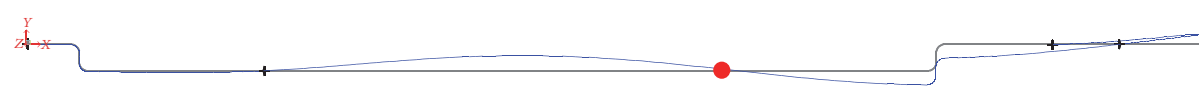

(a) Plane view

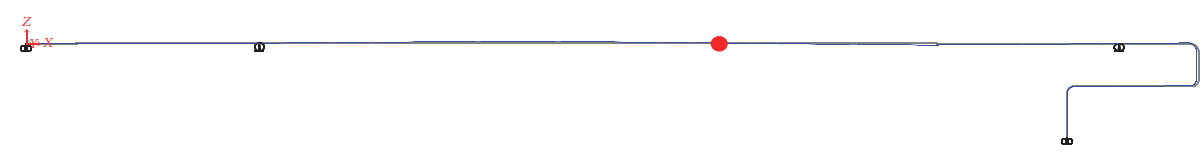

(b) Elevation view

FIgURE 4: Third mode shape.

\section{Design of Dampers}

We utilized a two-step process to design a damper to reduce the vibration of the piping system. The first step is the calculation of the mass ratio, frequency ratio, and damping ratio of the damper. Then, in the second step, the specific design of the SBD is done. The design parameters of the damper are determined from the eigenvalue analysis results. According to Den Hartog's formula, the mass ratio, optimum frequency ratio, and optimum damping ratio are calculated as follows [16]:

$$
\begin{aligned}
\mu & =\frac{8 \xi_{\mathrm{eff}}^{2}}{1-4 \xi_{\mathrm{eff}}^{2}}, \\
\gamma_{\mathrm{opt}} & =\frac{1}{1+\mu}, \\
\xi_{\mathrm{opt}} & =\frac{1}{2} \sqrt{\frac{3 \mu / 2}{1+3 \mu},}
\end{aligned}
$$




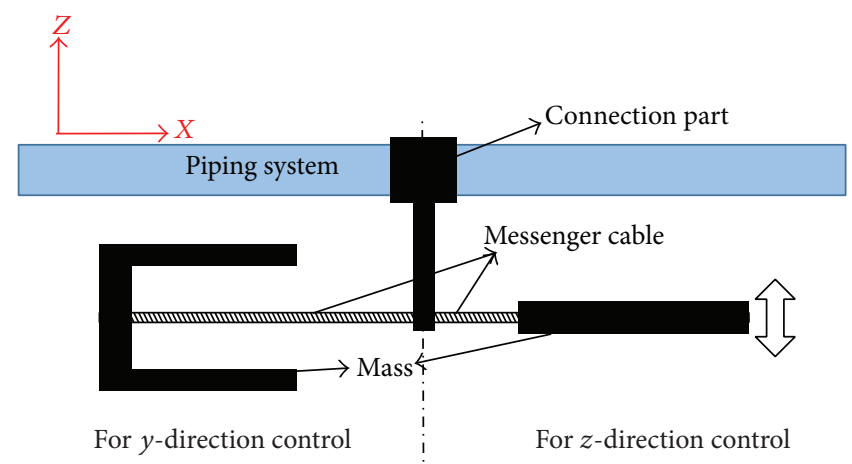

FIgURE 5: Components of a Stockbridge damper.

where $\xi_{\text {eff }}$ is the effective damping ratio of the piping system, $\mu$ is the mass ratio, $\gamma_{\text {opt }}$ is the optimum frequency ratio, and $\xi_{\text {opt }}$ is the optimum damping ratio of the damper.

3.1. Stockbridge Damper. The SBD is composed of a mass part and messenger cable parts, as shown in the SBD cross section in Figure 5. The messenger cable is comprised of several steel wire strands and can dissipate the energy of the vibration through strand friction. In this paper, both sides of the SBD play a different role. The left part of the SBD reduces the $y$ direction vibration of the piping system, while the right part of the SBD suppresses the $z$-direction vibration of the piping system.

The equation of motion for SBD is given as

$$
M \ddot{x}+C \dot{x}+K x=0,
$$

where $M$ is the mass matrix, $C$ is the damping matrix, and $K$ is the stiffness matrix; and $\ddot{x}, \dot{x}$, and $x$ are the acceleration, velocity, and displacement of the SBD, respectively.

Undamped natural frequencies of the SBD system are obtained by [11]

$$
\begin{aligned}
& \omega_{1}=\left(\frac{h-a}{2 m \rho}\right)^{1 / 2}, \\
& \omega_{2}=\left(\frac{h+a}{2 m \rho}\right)^{1 / 2}, \\
& \rho=\left(\frac{r}{l}\right)^{2}, \\
& h=(1+\rho) k_{11}+\frac{k_{22}}{l^{2}}-2 \frac{k_{12}}{l}, \\
& a=\sqrt{h^{2}-\frac{4 \rho}{l^{2}}\left(k_{11} k_{22}-k_{12}^{2}\right),}
\end{aligned}
$$

where $\omega_{i}$ is the frequency of the SBD, $m$ is the mass, $r$ is the radius of gyration of mass, $l$ is the distance between the attachment point and the center of gravity of the mass, and $k_{i j}$ is the bending stiffness of messenger cable (where $i, j=1,2,3, \ldots)$. The basic design for the SBD was calculated using the above equations, and the target frequency was then
TABLE 4: Properties of SBD.

\begin{tabular}{lcc}
\hline Parameters & SBD $(y$-direction $)$ & SBD $(z$-direction $)$ \\
\hline Mass ratio & 0.022 & 0.024 \\
Mass $(\mathrm{kg})$ & 4.0 & 4.0 \\
Frequency ratio & 0.978 & 0.977 \\
Damping ratio & 0.15 & 0.15 \\
Messenger cable length $(\mathrm{m})$ & 0.24 & 0.21 \\
\hline
\end{tabular}

adjusted by fine tuning. The properties of the SBD are shown in Table 4.

\section{Base Excitation}

4.1. Sine Sweep Wave. In order to investigate the frequency ranges of the piping system, a sine sweeping wave with peak acceleration of $1.0 \mathrm{~m} / \mathrm{sec}^{2}$ varying from $0.1 \mathrm{~Hz}$ to $20 \mathrm{~Hz}$ was applied to the nuclear power plant piping system with and without the SBD for $y$ - and $z$-directions (Figure 6).

4.2. Earthquake Ground Motion. In this study, recorded earthquakes were used to verify that the proposed SBD can reduce the vibration response of the nuclear power plant piping system. El Centro, California, and Northridge earthquakes were selected for dynamic analysis. El Centro earthquakes of the $x$-, $y$-, and $z$-axis direction were used to check the horizontal and vertical behavior of the piping system. The earthquake time history has a 50 -second duration and 0.02-second time steps. Peak ground accelerations were scaled to $0.34 \mathrm{~g}, 0.21 \mathrm{~g}$, and $0.21 \mathrm{~g}$ for the $x$-, $y$-, and $z$ axis directions, respectively. The time history acceleration and response spectrum of the ground motion in each direction were shown in Figure 7. While the horizontal earthquakes have an energy distribution between $1 \mathrm{~Hz}$ and $5 \mathrm{~Hz}$, vertical earthquakes have more vibration energy in $10 \mathrm{~Hz}$.

Vertical earthquakes were scaled to fit $1 / 2$ of PGA of the horizontal ground motion for California and Northridge earthquakes. Therefore, the PGAs of California and Northridge earthquakes were scaled from $0.15 \mathrm{~g}$ to $0.075 \mathrm{~g}$ and from $0.34 \mathrm{~g}$ to $0.17 \mathrm{~g}$ in the vertical direction, respectively. The ground motion of each direction and response spectrum are shown in Figures 8 and 9. 


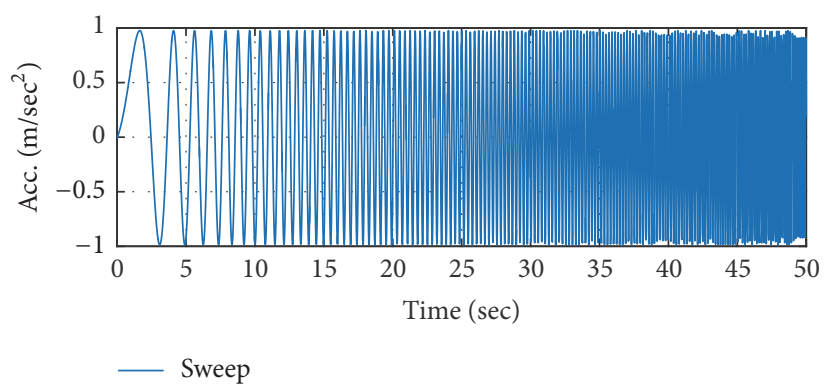

(a) Sweep wave

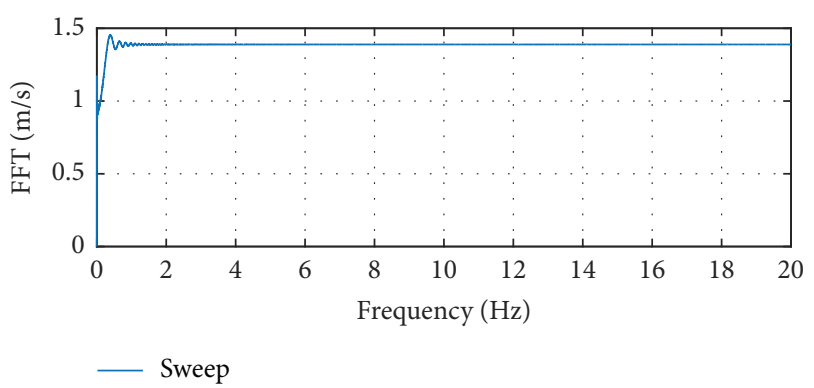

(b) FFT

Figure 6: Sine sweep wave and its FFT.
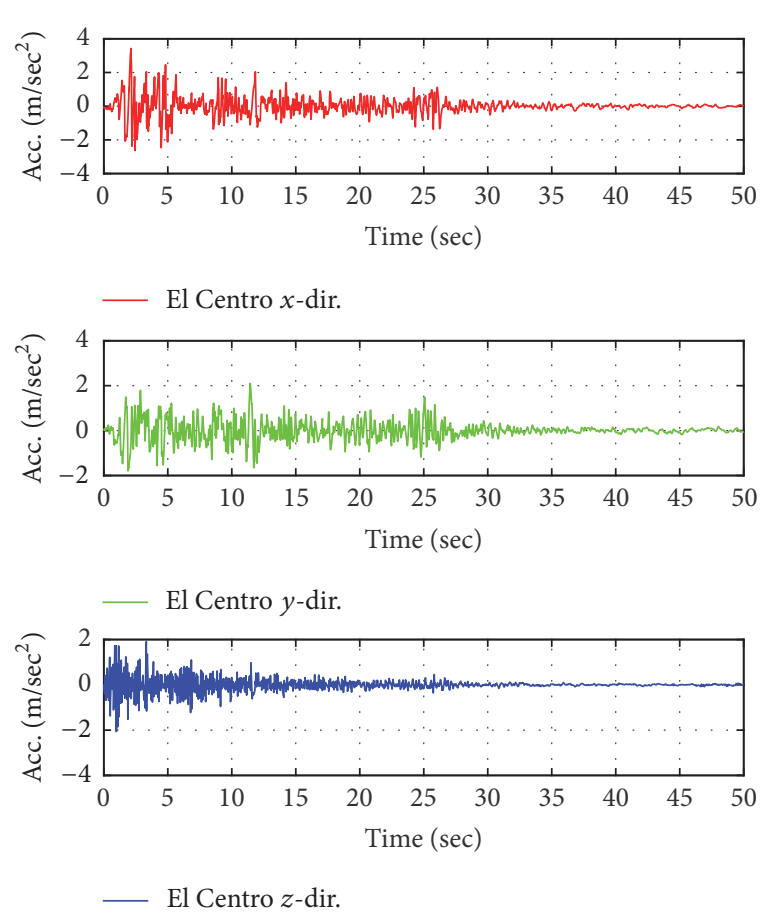

(a) El Centro earthquake

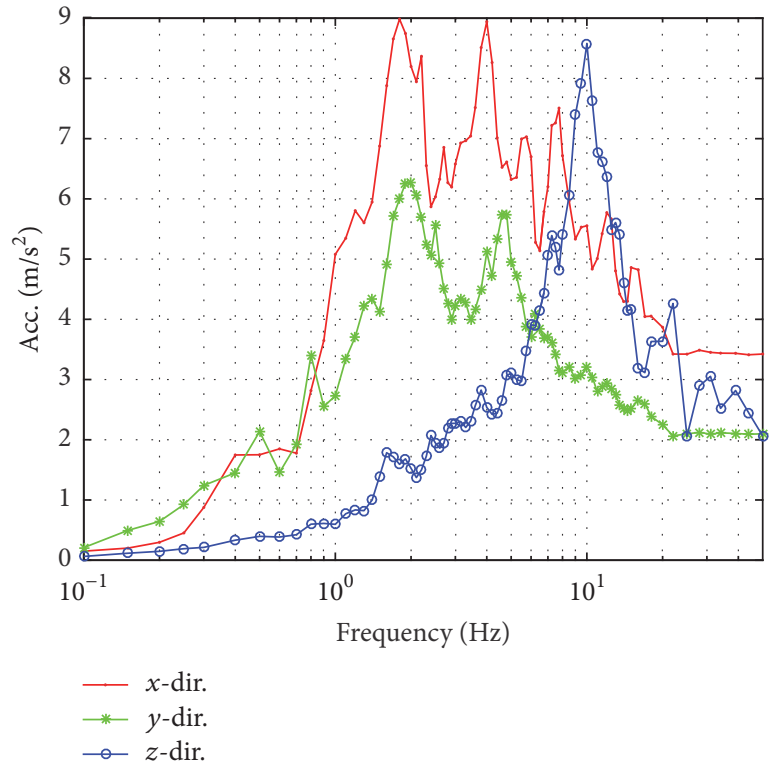

(b) Response spectrum

FIgURE 7: El Centro earthquake and its FFT.

\section{Results and Discussion}

5.1. Response of Piping System Subjected to Sine Sweep Excitation. The accelerations of the piping system were measured in the maximum amplitude when the SBD was not installed on the piping system (red spot in Figures 2-4). Figure 10 shows the time history response and response spectrum of the $y$-directional response after inputting the signal in the $y$ direction. This shows that the first mode $(1.9 \mathrm{~Hz})$ is dominant. However, in the case of Figure 11, the $z$-direction response of the piping system after applying the $y$-directional wave is shown. This simultaneously shows the peak in the first mode shape at $1.9 \mathrm{~Hz}$ ( $y$-directional mode) and the second mode shape at $2.3 \mathrm{~Hz}$ ( $z$-directional mode) of the piping system under the sine sweep wave because the modal shape of the piping system was mixed. Figure 13 also shows the same trend with inverse load conditions from those in Figure 11. Figure 12 shows the same trend with Figure 10. From the results of the sine sweep wave, it is confirmed that the proposed SBD can reduce the vibration in all frequency domains $(0.1 \mathrm{~Hz}$ to $20 \mathrm{~Hz}$ ). Based on the given results, it is evident that having a wide frequency range is one advantage of the SBD.

5.2. Response of Piping System Subjected to Earthquakes. An earthquake analysis was performed to investigate the applicability with respect to the piping system and to confirm the vibration mitigation of the piping system with and without the SBD under the recorded earthquakes. The accelerations of the piping system were measured for the maximum amplitude when the SBD was not installed on the piping system (red spot in Figures 2-4). Figure 14 shows the time history response and frequency domain response of the piping system with and without the SBD in the $x_{-}^{-}, y^{-}$, and 

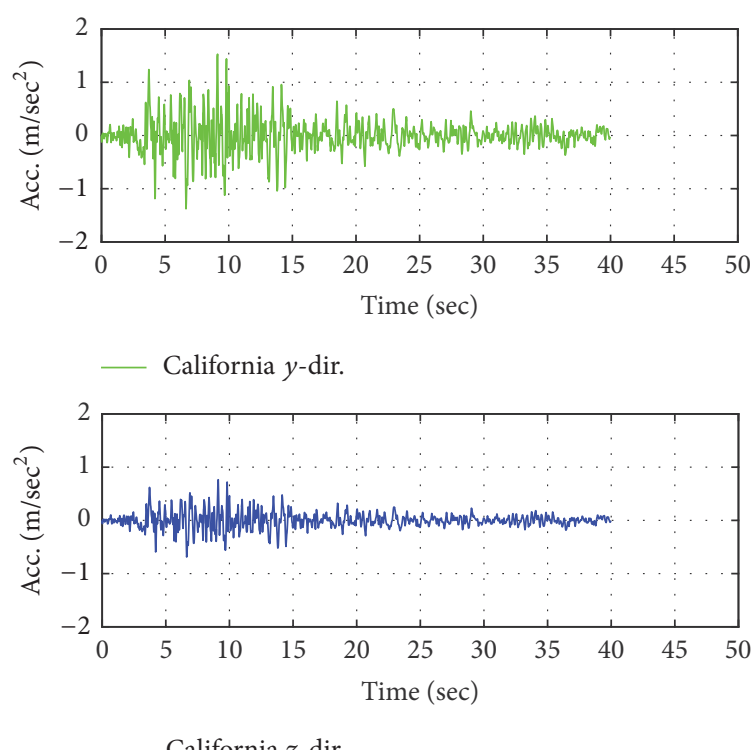

(a) California earthquake

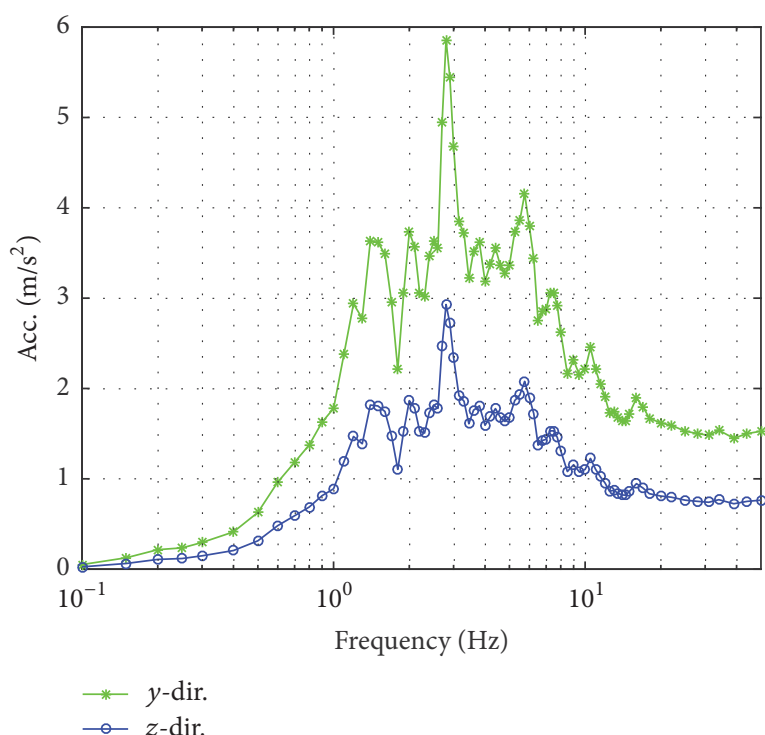

(b) Response spectrum

FIGURE 8: California earthquake and its response spectrum.

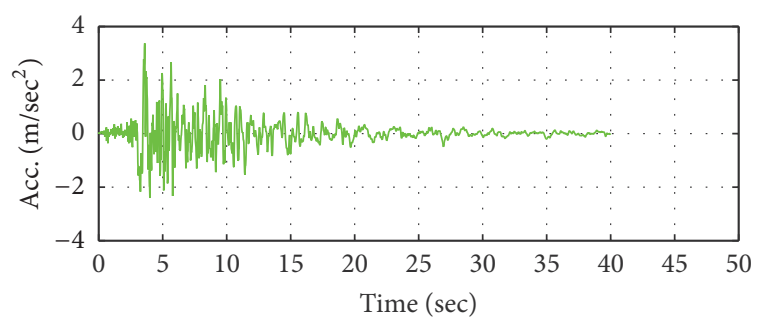

_ Northridge $y$-dir.

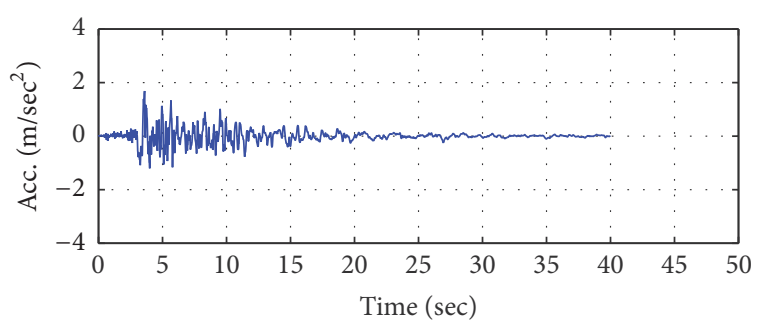

- Northridge $z$-dir.

(a) Northridge earthquake

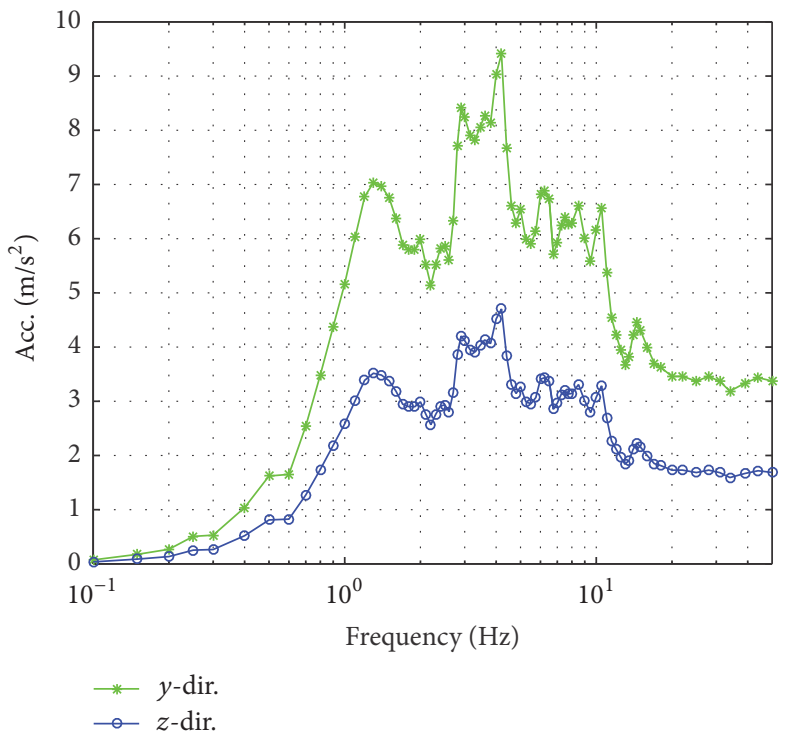

(b) Response spectrum

FIgURE 9: Northridge earthquake and its response spectrum.

$z$-axis directions when El Centro earthquake was applied to the system.

The $x$-directional vibration of the piping system appeared to be almost invisible when the SBD was installed (Figure 14(a)). The maximum acceleration decreased from $1.58 \mathrm{~m} / \mathrm{s}^{2}$ to $0.02 \mathrm{~m} / \mathrm{s}^{2}$, and the root mean square (RMS) was reduced from $0.13 \mathrm{~m} / \mathrm{s}^{2}$ to $0.002 \mathrm{~m} / \mathrm{s}^{2}$ in the $x$-direction. Each decreasing ratio was $99.0 \%$ and $98.5 \%$, respectively. In the case of the $y$-direction response, the maximum acceleration decreased from $6.52 \mathrm{~m} / \mathrm{s}^{2}$ to $1.97 \mathrm{~m} / \mathrm{s}^{2}$, and RMS was reduced from $1.24 \mathrm{~m} / \mathrm{s}^{2}$ to $0.29 \mathrm{~m} / \mathrm{s}^{2}$ when the SBD was applied. Table 5 shows the maximum acceleration, RMS response, and its decreasing ratio where the SBD was installed. In this paper, the maximum acceleration and RMS were used to evaluate the vibration of the piping system. The RMS are calculated as follows:

$$
\mathrm{RMS}=\sqrt{\frac{1}{N} \sum_{n=1}^{N}\left|\mathrm{acc}_{n}\right|^{2}},
$$


TABLE 5: Results for El Centro earthquake.

\begin{tabular}{ccccccc}
\hline \multirow{2}{*}{ Direction } & \multicolumn{3}{c}{ Maximum acceleration $\left(\mathrm{m} / \mathrm{s}^{2}\right)$} & \multicolumn{3}{c}{ RMS acceleration $\left(\mathrm{m} / \mathrm{s}^{2}\right)$} \\
& Uncontrolled & Controlled & Decreasing ratio (\%) & Uncontrolled & Controlled & Decreasing ratio (\%) \\
\hline$x$ & 1.577 & 0.016 & 99.0 & 0.126 & 0.002 & 98.5 \\
$y$ & 6.523 & 1.973 & 69.8 & 1.237 & 0.285 & 76.9 \\
$z$ & 3.538 & 3.145 & 11.1 & 0.460 & 0.260 & 43.5 \\
\hline
\end{tabular}

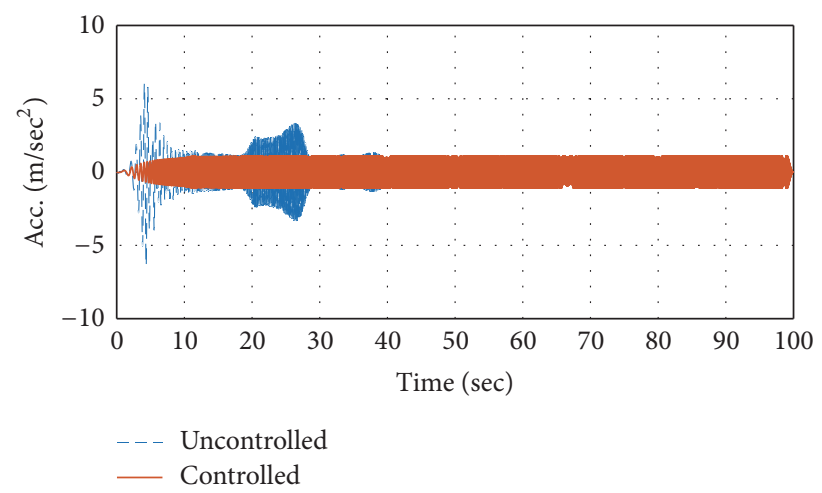

(a) Acceleration response

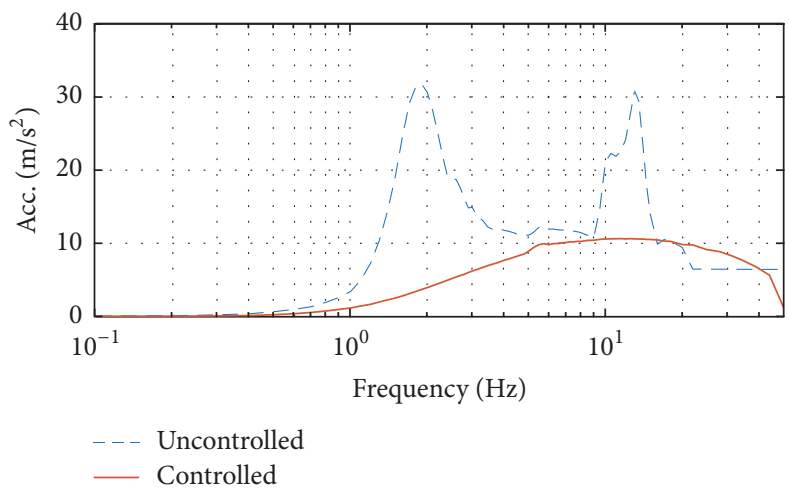

(b) Response spectrum

FIGURE 10: Response of piping system subjected to sine sweep wave ( $y$-direction load and response).

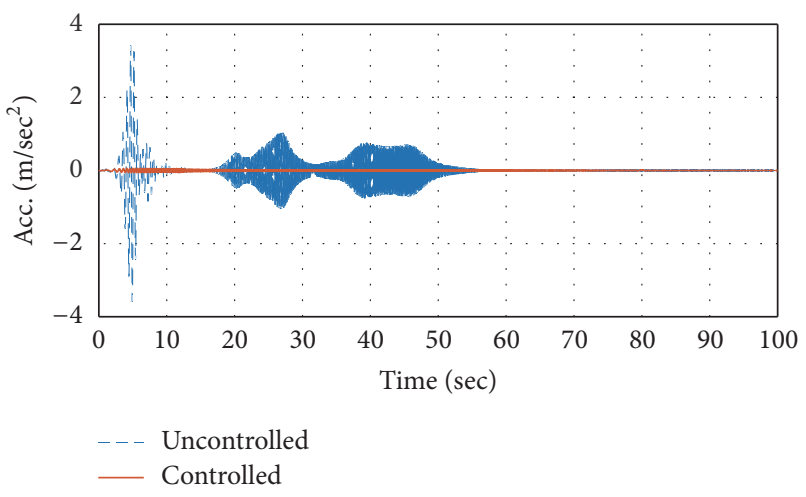

(a) Acceleration response

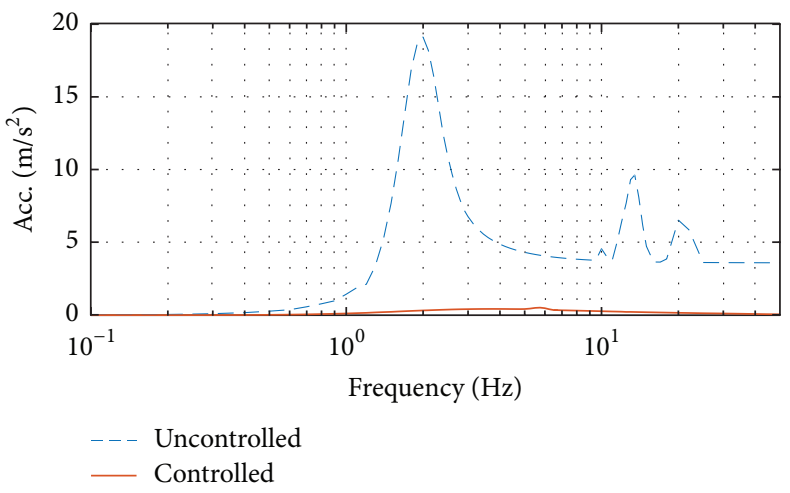

(b) Response spectrum

FIGURE 11: Response of piping system subjected to sine sweep wave ( $y$-direction load versus $z$-direction response).

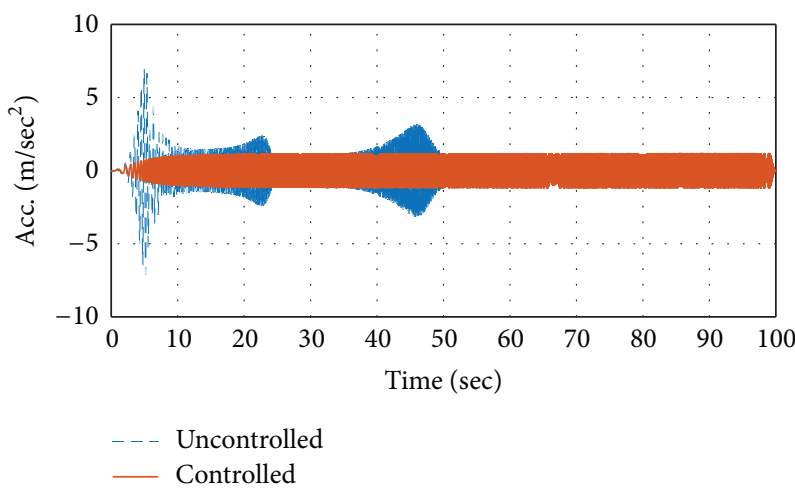

(a) Acceleration response

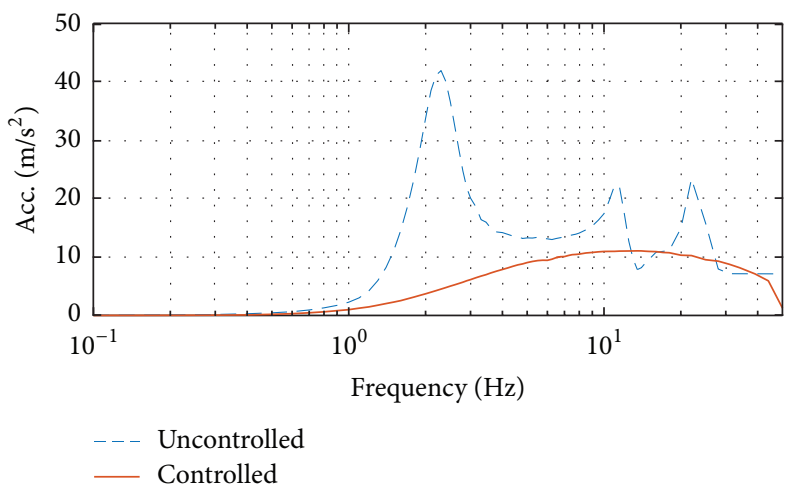

(b) Response spectrum

FIGURE 12: Response of piping system subjected to sine sweep wave ( $z$-direction load and response). 


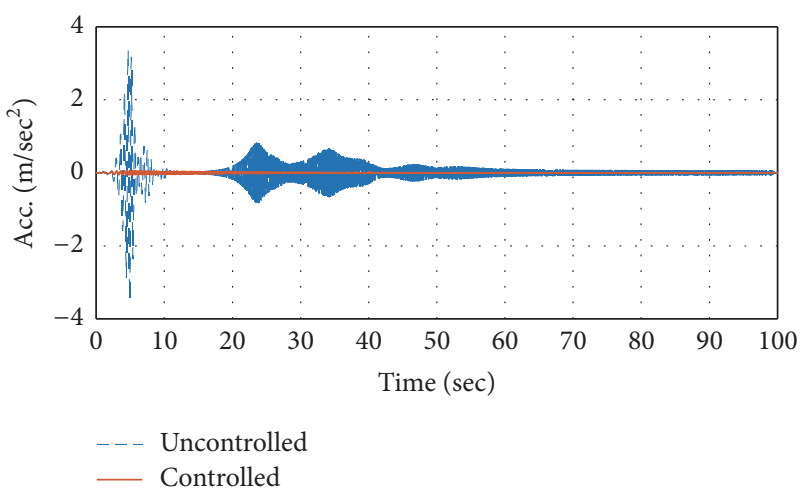

(a) Acceleration response

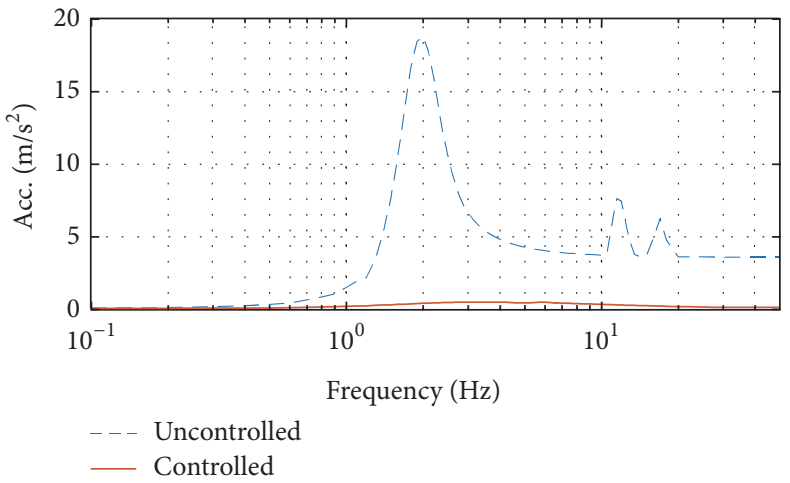

(b) Response spectrum

FIGURE 13: Response of piping system subjected to sine sweep wave ( $z$-direction load versus $y$-direction response).
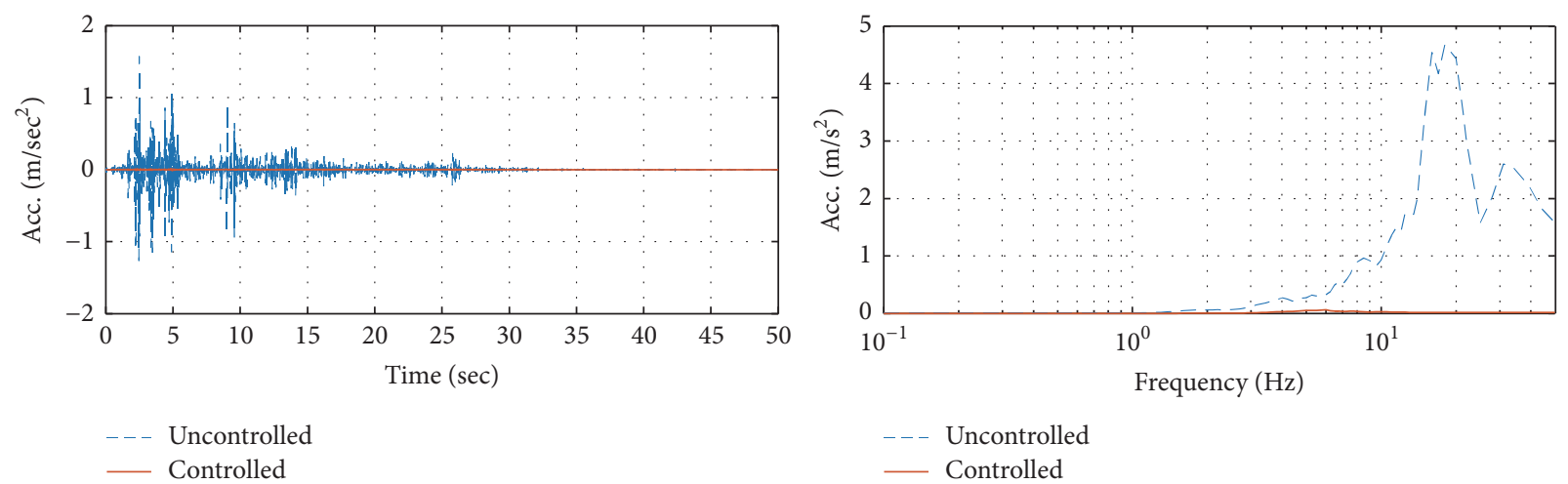

(a) $x$-direction
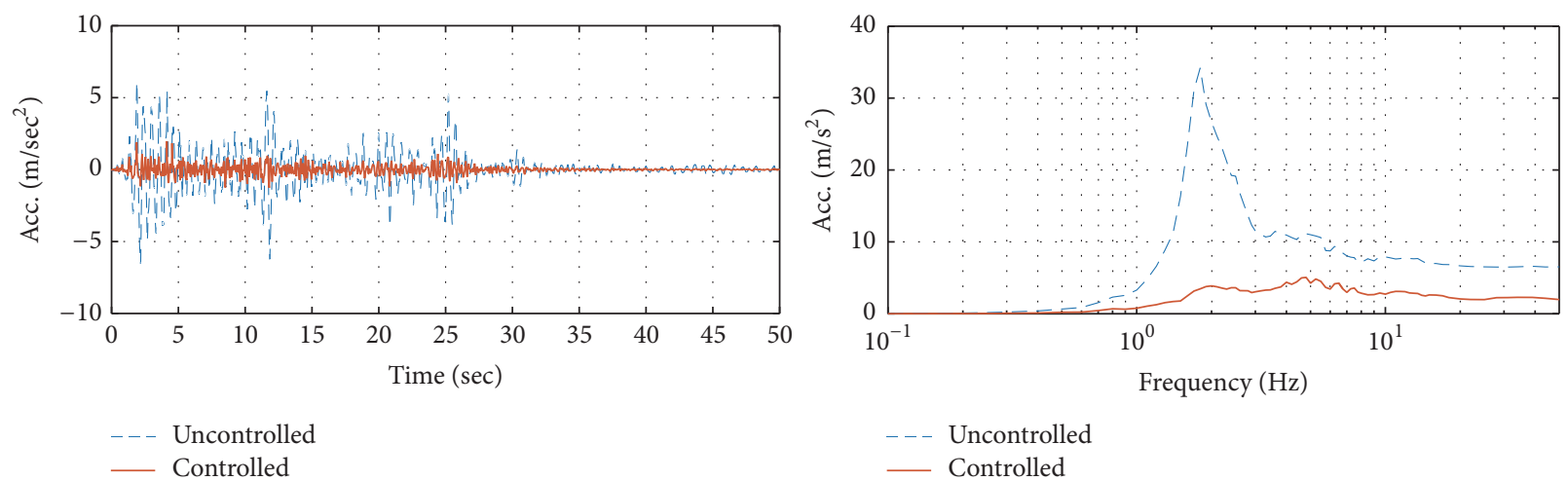

(b) $y$-direction
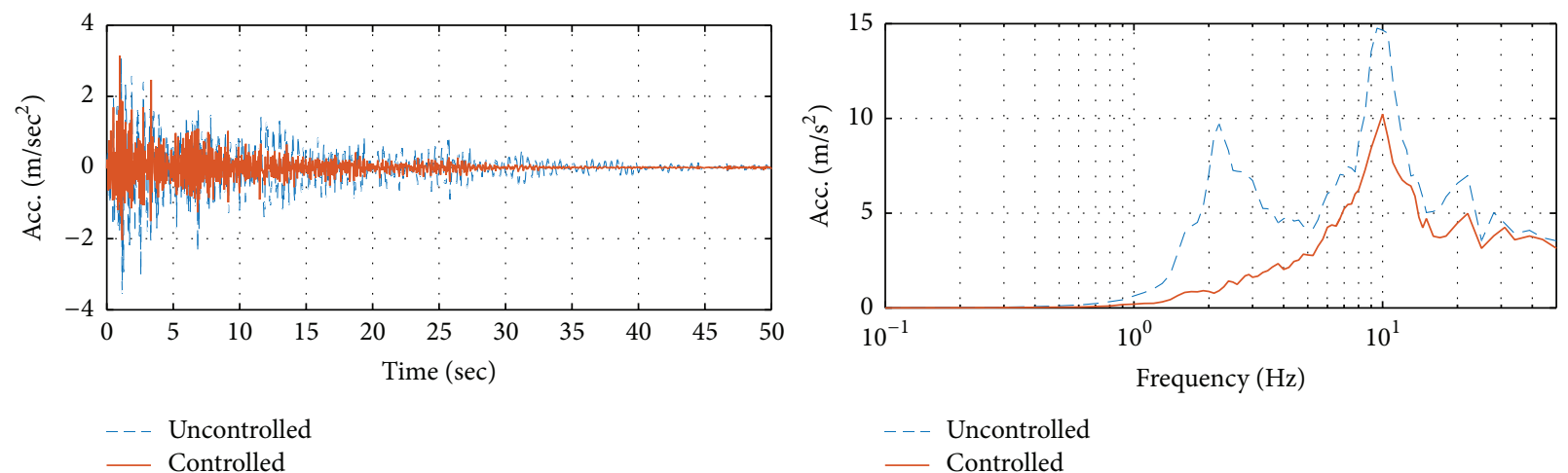

(c) $z$-direction

FIGURE 14: Response of piping system subjected to El Centro earthquake. 

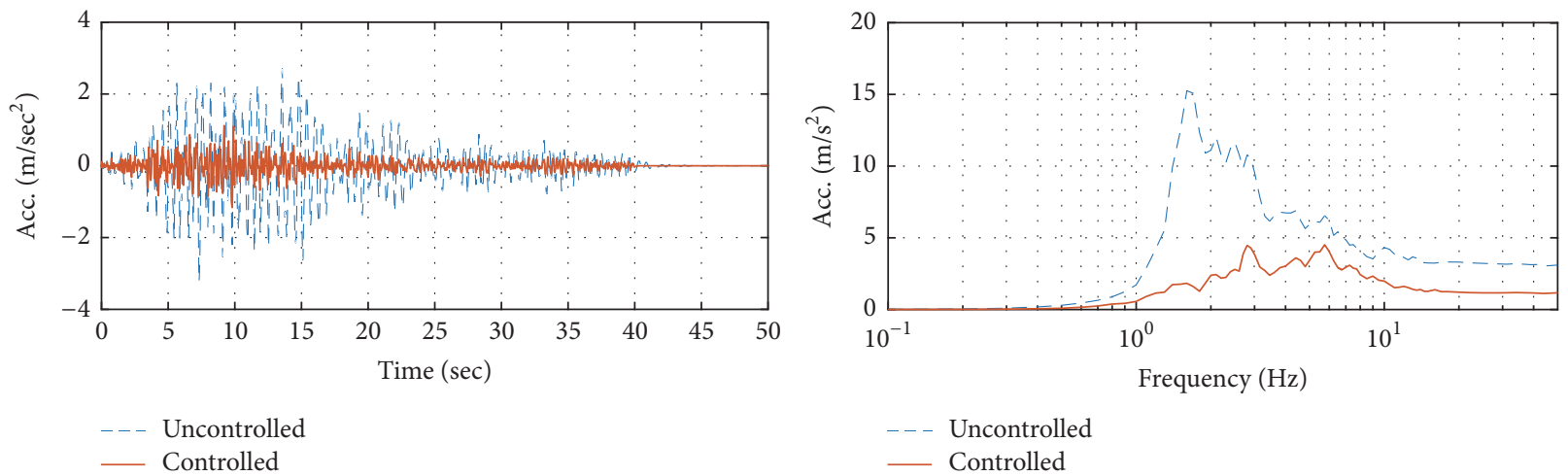

(a) $y$-direction
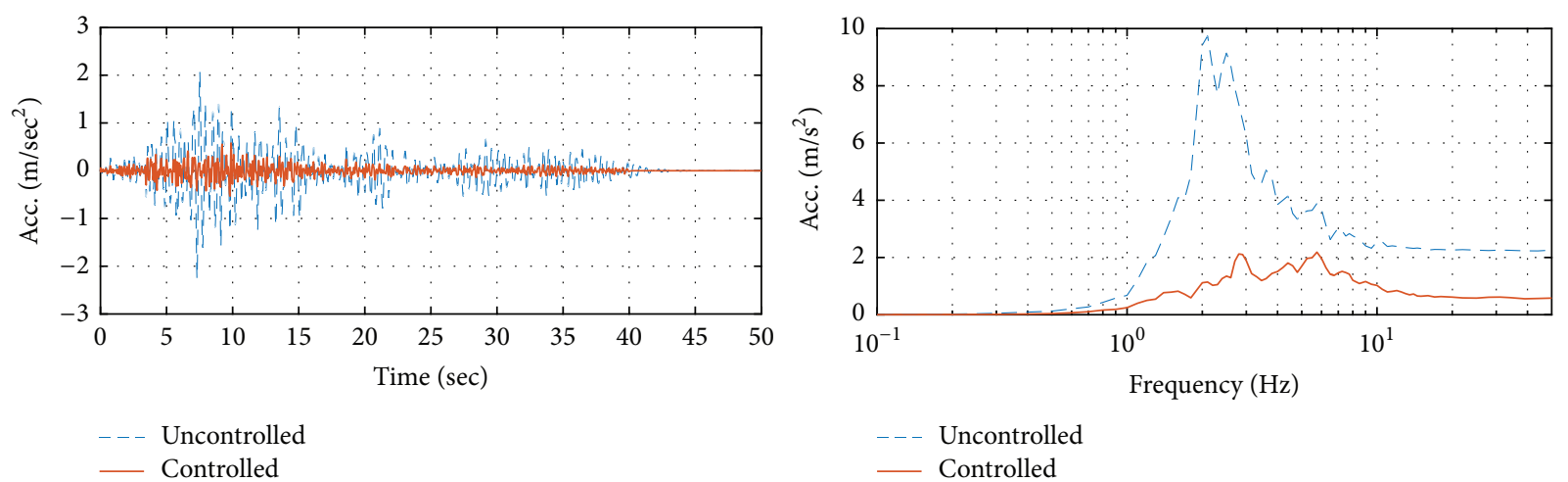

(b) $z$-direction

FIGURE 15: Response of piping system subjected to California earthquake.

where $N$ is the length of data and $\operatorname{acc}_{n}$ is the acceleration of $n$th time step. The RMS represents the amplitude related with an energy amount, which indicates the destructive ability of the vibration.

The $z$-directional El Centro earthquake shows a large amount of energy on the adjacent $10 \mathrm{~Hz}$, unlike earthquakes of the other directions (Figure 7(a)). Although the proposed SBD was not designed with respect to that frequency area, nevertheless the control effects of the damper can be confirmed based on the peak acceleration and response spectrum. Since the SBD was not designed for $x$ directional response, the control system has some effects on the responses of $x$-directions. This phenomenon can be explained by the reason of the piping system having complex modal shapes and coupled responses. In other words, if $y$ direction and $z$-direction responses of the piping system can occur by earthquake in $x$-direction, then it is obvious that the SBD can be capable of suppressing the vibration in $x$ direction with the other both directions instead of not being designed for $x$-direction.

Figures 15 and 16 show the time history response and frequency domain response of the nuclear power plant piping system with and without the SBD in the $y$ - and $z$-axis directions under California and Northridge earthquakes. The acceleration response of both earthquakes was considerably suppressed by the proposed SBD. With respect to California earthquake, the maximum acceleration of the piping system decreased from $3.22 \mathrm{~m} / \mathrm{s}^{2}$ to $1.17 \mathrm{~m} / \mathrm{s}^{2}$, and RMS response was reduced from $0.67 \mathrm{~m} / \mathrm{s}^{2}$ to $0.19 \mathrm{~m} / \mathrm{s}^{2}$ in the $y$-direction. Each decreasing ratio was $63.8 \%$ and $71.6 \%$, respectively. In the case of the $z$-direction, the decreasing ratio of the maximum acceleration and RMS response decreased by $74.3 \%$ and $73.4 \%$, respectively.

This demonstrates the good control performance of the SBD for Northridge earthquake, as shown in Figure 16. The maximum acceleration and RMS response decreased by $60.2 \%$ and $74.0 \%$ in the $y$-direction, respectively, and $58.5 \%$ and $71.9 \%$ in the $z$-direction, respectively. The maximum acceleration and RMS response for each earthquake are shown in Tables 6 and 7.

Figure 17 shows the response of the piping system in the $z$ direction under the $y$-directional El Centro earthquake and the response of the piping system in the $y$-direction under the $z$-directional El Centro earthquake. It can be seen that the response reduction of the piping system in Figure 17 is more noticeable than the trend shown in Figures 1416. While the control effects of the SBD in Figures 14-16 show extremely effective behavior at tuned frequencies (first and second mode), the frequency response of Figure 17 is $2 \mathrm{~Hz}$, which shows a wide range of frequency response. The response decreasing ratio of the piping system was large when the load direction and response direction were different. This is because the SBD in this paper was actually designed for first and second frequency modes; therefore, the SBD 
TABLE 6: Results for California earthquake.

\begin{tabular}{ccccccc}
\hline \multirow{2}{*}{ Direction } & \multicolumn{3}{c}{ Maximum acceleration $\left(\mathrm{m} / \mathrm{s}^{2}\right)$} & \multicolumn{3}{c}{ RMS acceleration (m/ $\left.\mathrm{s}^{2}\right)$} \\
& Uncontrolled & Controlled & Decreasing ratio (\%) & Uncontrolled & Controlled & Decreasing ratio (\%) \\
\hline$y$ & 3.217 & 1.165 & 63.8 & 0.667 & 0.190 & 71.6 \\
$z$ & 2.256 & 0.580 & 74.3 & 0.350 & 0.093 & 73.4 \\
\hline
\end{tabular}

TABLE 7: Results for Northridge earthquake.

\begin{tabular}{ccccccc}
\hline \multirow{2}{*}{ Direction } & \multicolumn{3}{c}{ Maximum acceleration $\left(\mathrm{m} / \mathrm{s}^{2}\right)$} & \multicolumn{3}{c}{ RMS acceleration (m/s $\left.{ }^{2}\right)$} \\
& Uncontrolled & Controlled & Decreasing ratio (\%) & Uncontrolled & Controlled & Decreasing ratio (\%) \\
\hline$y$ & 7.252 & 2.889 & 60.2 & 1.190 & 0.310 & 74.0 \\
$z$ & 3.576 & 1.484 & 58.5 & 0.545 & 0.153 & 71.9 \\
\hline
\end{tabular}
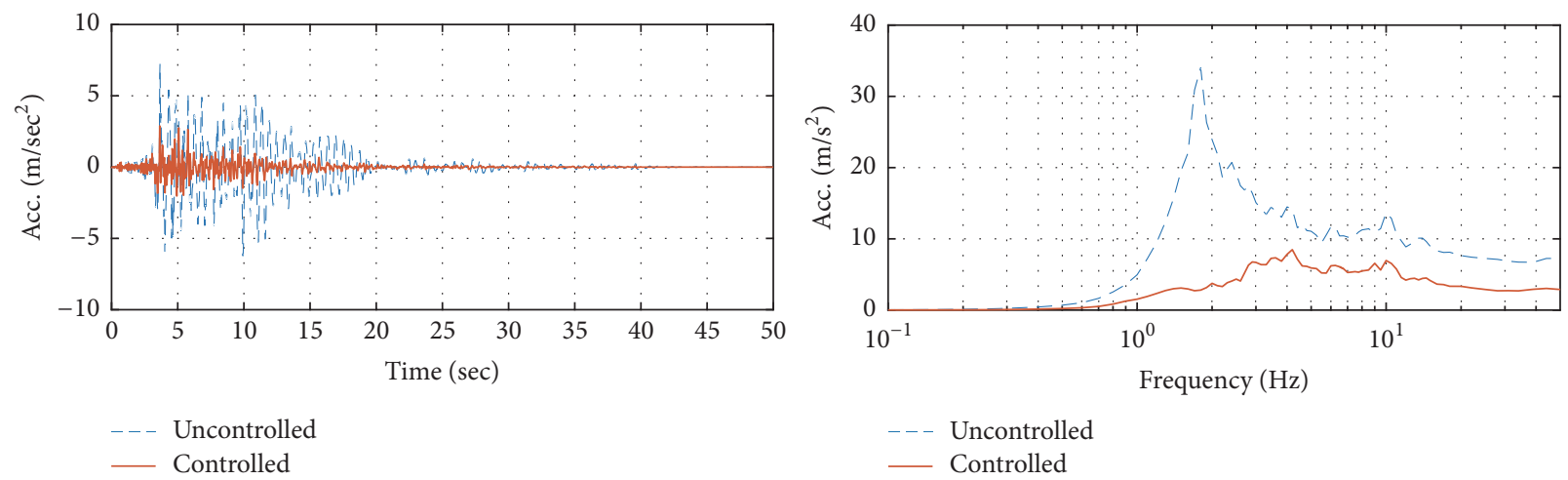

(a) $y$-direction
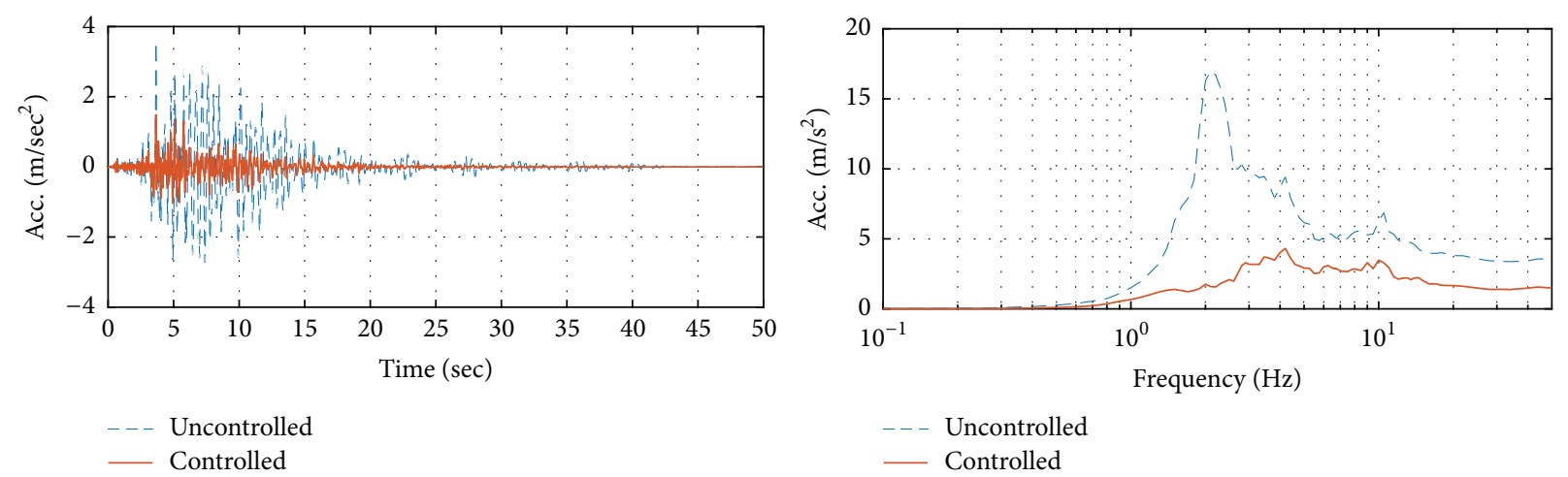

(b) $z$-direction

FIGURE 16: Response of piping system subjected to Northridge earthquake.

extremely suppressed the vibration of the piping system. However, that the SBD can also reduce vibrations beyond the design frequency range was already confirmed in our previous results. The results of California earthquake also show a similar trend with those of El Centro earthquake (Figure 18). The directional results for both earthquakes are summarized in Tables 8 and 9. The reduction ratio of all responses is more than $90 \%$.

\section{Conclusion}

From the study performed, SBD is recommended to control the seismic response of NPP piping system. Effect of SBD to control the seismic response of piping system is demonstrated considering El Centro, California, and Northridge earthquake excitations. The piping system (ASCE CLASS1 SA312 GRADE TP316 SCH) was modeled under the same conditions as in an actual nuclear power plant. The SBD was designed for low order frequency modes using free vibration analysis results. The controlled responses of the time and frequency domain were compared with uncontrolled responses of the piping system under horizontal and vertical earthquakes. It was confirmed through sine sweep wave analysis that the proposed damper can reduce wide frequency vibration responses. 

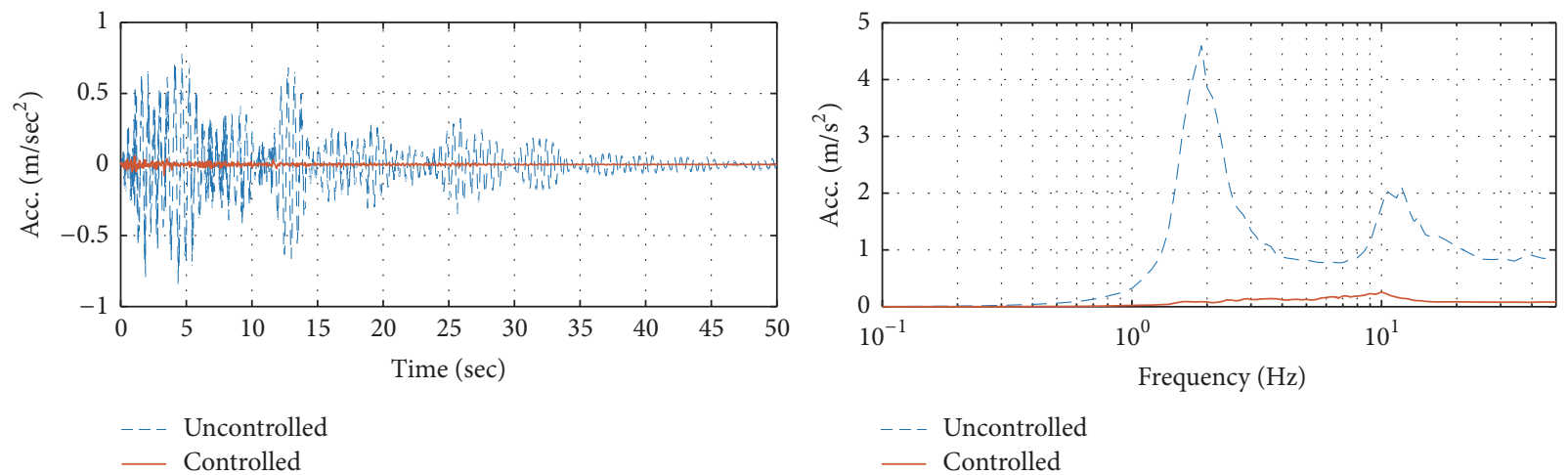

(a) $y$-direction response under $z$-direction load
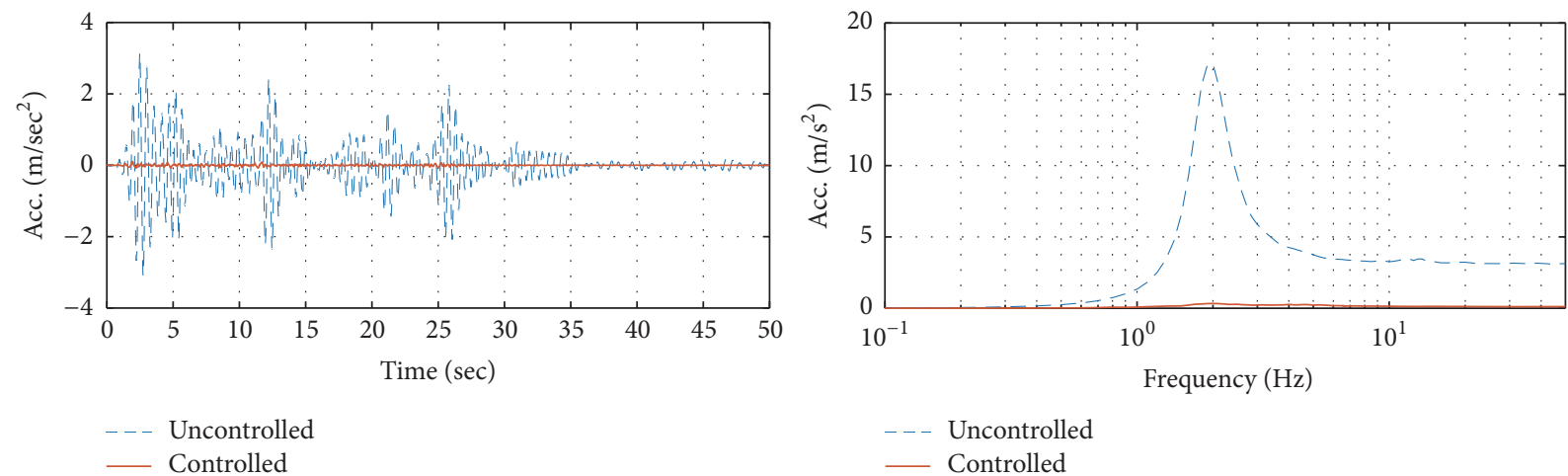

(b) $z$-direction response under $y$-direction load

FIGURE 17: Response of piping system subjected to El Centro earthquake.
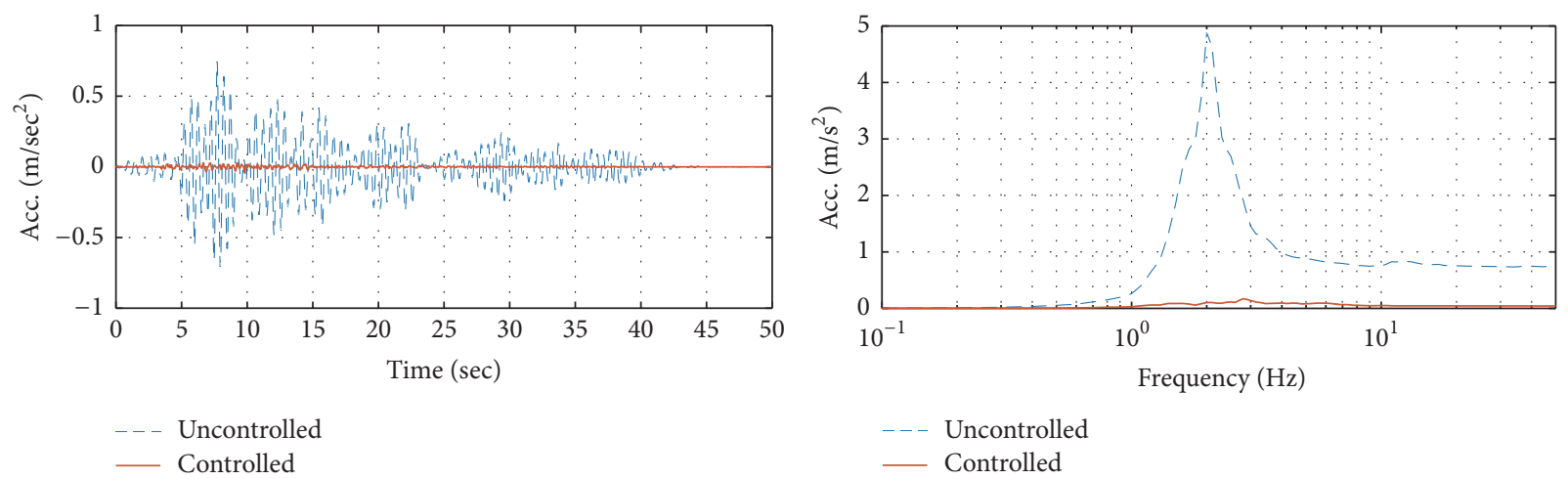

(a) $y$-direction response under $z$-direction load
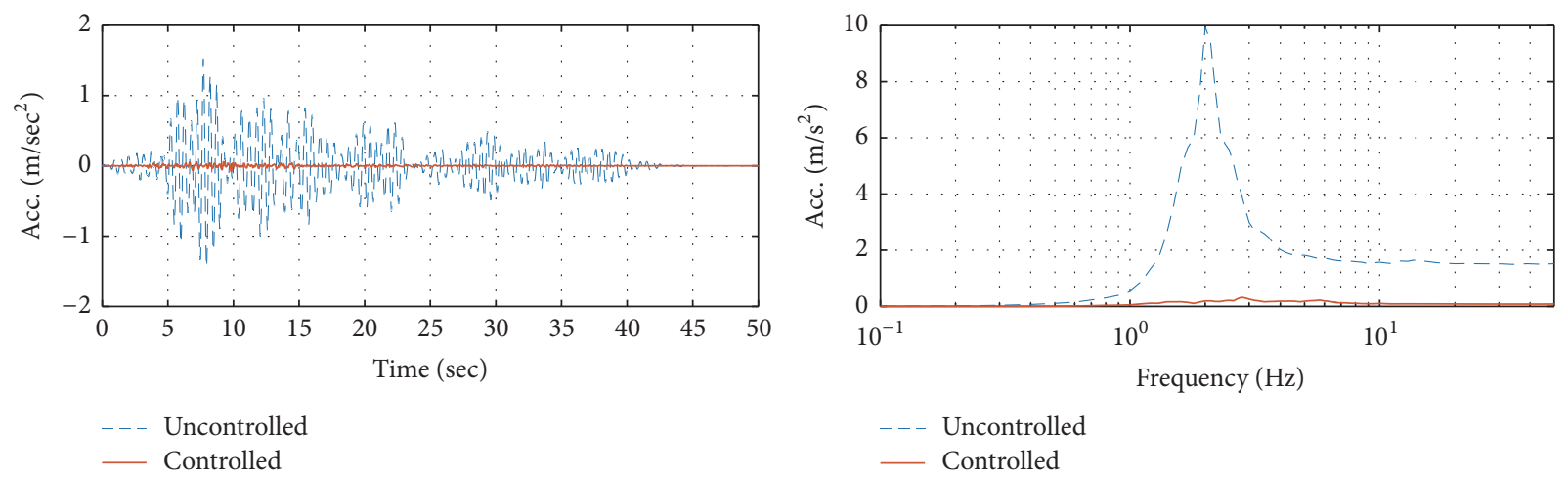

(b) $z$-direction response under $y$-direction load

FIGURE 18: Response of piping system subjected to California earthquake. 
TABLE 8: Directional results for El Centro earthquake.

\begin{tabular}{lccccccc}
\hline \multicolumn{2}{c}{ Direction } & \multicolumn{3}{c}{ Maximum acceleration $\left(\mathrm{m} / \mathrm{s}^{2}\right)$} & \multicolumn{3}{c}{ RMS acceleration (m/s $\left.\mathrm{s}^{2}\right)$} \\
Load & Resp. & Uncontrolled & Controlled & Decreasing ratio (\%) & Uncontrolled & Controlled & Decreasing ratio (\%) \\
\hline$z$ & $y$ & 0.838 & 0.082 & 90.3 & 0.169 & 0.008 & 95.2 \\
$y$ & $z$ & 3.132 & 0.114 & 96.3 & 0.618 & 0.018 & 97.1 \\
\hline
\end{tabular}

TABLE 9: Directional results for California earthquake.

\begin{tabular}{lccccccc}
\hline \multicolumn{2}{c}{ Direction } & \multicolumn{3}{c}{ Maximum acceleration $\left(\mathrm{m} / \mathrm{s}^{2}\right)$} & \multicolumn{3}{c}{ RMS acceleration $\left(\mathrm{m} / \mathrm{s}^{2}\right)$} \\
Load & Resp. & Uncontrolled & Controlled & Decreasing ratio (\%) & Uncontrolled & Controlled & Decreasing ratio (\%) \\
\hline$z$ & $y$ & 0.745 & 0.043 & 94.2 & 0.151 & 0.006 & 96.0 \\
$y$ & $z$ & 1.527 & 0.085 & 94.5 & 0.306 & 0.012 & 96.1 \\
\hline
\end{tabular}

In the earthquake results, the maximum acceleration declined by about $99 \%, 69 \%$, and $11 \%$ in each direction under El Centro earthquake, respectively. The maximum accelerations decreased by $63 \%$ in $y$-direction and $74 \%$ in $z$-direction under California earthquake. In the case of the Northridge earthquake, reductions of each acceleration were found to be $60 \%$ and $58 \%$ in $y$-direction and $z$-direction, successively.

From the earthquake response analysis results, it was found that the proposed SBD can reduce not only the targeted vibration modes of the piping system but also other modes under earthquakes. Most importantly, it was also confirmed that the proposed SBD can effectively reduce the vibration of a nuclear power plant piping system under earthquakes.

\section{Competing Interests}

The authors declare that they have no competing interests.

\section{Acknowledgments}

This work was supported by the National Research Foundation of Korea Grant funded by the Korean Government (NRF-2014R1A2A1A10049538) and the Nuclear Power Core Technology Development Program of the Korea Institute of Energy Technology Evaluation and Planning (KETEP) grant financial resource from the Ministry of Trade, Industry \& Energy, Republic of Korea (no. 20131520400080).

\section{References}

[1] M. Kunieda, T. Chiba, and H. Kobayashi, "Positive use of damping devices for piping systems-some experiences and new proposals," Nuclear Engineering and Design, vol. 104, no. 2, pp. 107-120, 1987.

[2] D. E. Olson and Y. K. Tang, "Decreasing snubber inservice inspection costs through snubber reduction and improved test limits," Nuclear Engineering and Design, vol. 107, no. 1-2, pp. 183199, 1988.

[3] N. Shimuzu, K. Suzuki, T. Watanabe, N. Ogawa, and H. Kobayashi, "Large scale shaking table test on modal responses of 3D piping system with friction support," Seismic Engineering ASME PVP, vol. 340, pp. 269-275, 1996.

[4] N. Park, G. DeGrassi, C. Hofmayer, and P. Bezler, "Analysis of nuclear piping system seismic tests with conventional and energy absorbing supports," in Proceedings of the International Conference on Structural Mechanics in Reactor Technology, pp. 269-275, Lyon, France, 1997.

[5] Y. M. Parulekar, G. R. Reddy, K. K. Vaze, and H. S. Kushwaha, "Elasto-plastic damper for passive control of seismic response of piping systems," BARC Internal Report, Reactor Safety Division, 2002.

[6] H. Abe, I. Ichihashi, K. Kuroda, T. Iwatsubo, and K. Tai, "Seismic proving test of heavy component with energy absorbing support," in Proceedings of the International Conference on Global Environment and Advanced Nuclear Power Plants, Kyoto, Japan, September 2003.

[7] K. Fujita, T. Kimura, and Y. Ohe, "Seismic response analysis of piping systems with nonlinear supports using differential algebraic equations," Journal of Pressure Vessel Technology, Transactions of the ASME, vol. 126, no. 1, pp. 91-97, 2004.

[8] S. V. Bakre, R. S. Jangid, and G. R. Reddy, "Seismic response of piping system with isolation devices," in Proceedings of the 13th World Conference on Earthquake Engineering, Paper no. 2676, Vancouver, Canada, August 2004.

[9] S. V. Bakre, R. S. Jangid, and G. R. Reddy, "Optimum X-plate dampers for seismic response control of piping systems," in Proceedings of the 4th International Conference on Structural Stability and Dynamics, 2012.

[10] G. Stockbridge, "Vibration Damper," Patent No. 1675391, USA Patent Office, 1925.

[11] H. Wagner, V. Ramamurti, R. V. R. Sastry, and K. Hartmann, "Dynamics of stockbridge dampers," Journal of Sound and Vibration, vol. 30, no. 2, pp. 207-220, 1973.

[12] J. Vecchiarelli, I. G. Currie, and D. G. Havard, "Computational analysis of aeolian conductor vibration with a stockbridge-type damper," Journal of Fluids and Structures, vol. 14, no. 4, pp. 489509, 2000.

[13] O. Barry, Finite element analysis of a single conductor with a stock bridge damper under aeolian vibration [M.S. thesis], Ryerson University, 2010.

[14] S. Urushadze, M. Pirner, S. Pospisil, and R. Kral, "Experimental and numerical verification of vortex-induced vibration of hangers on the footbridge," in Proceedings of the 18th International Conference, Engineering Mechanics, Svratka, Czech Republic, 2012.

[15] N. Barbieri and R. Barbieri, "Dynamic analysis of stockbridge damper," Advances in Acoustics and Vibration, vol. 2012, Article ID 659398, 8 pages, 2012.

[16] J. P. Den Hartog, Mechanical Vibrations, McGraw-Hill Book Company, New York, NY, USA, 3rd edition, 1947. 

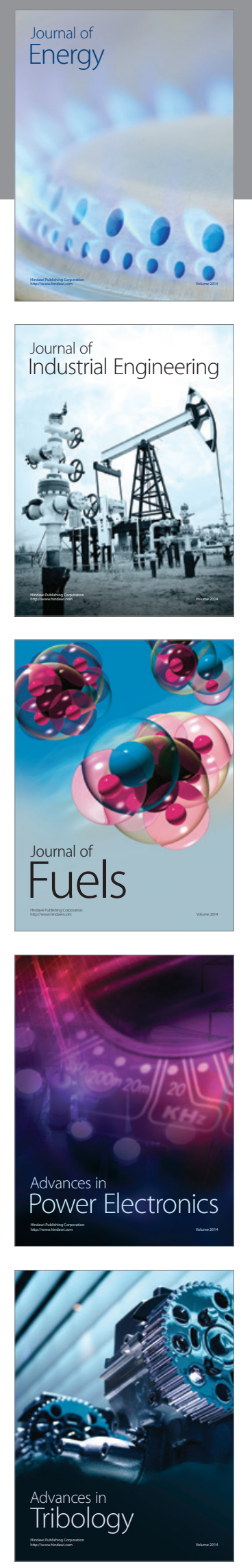
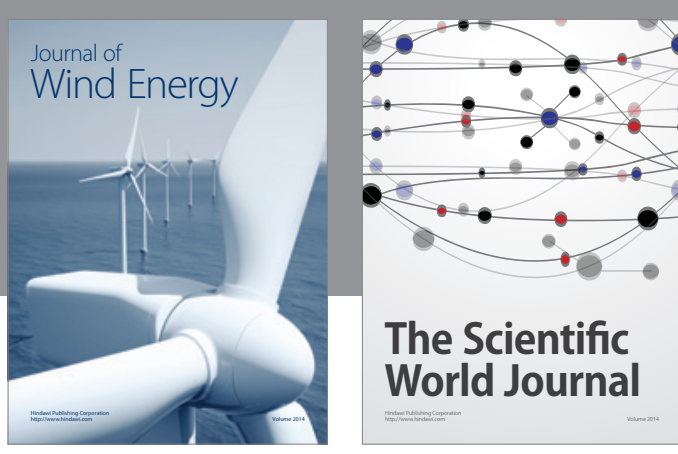

The Scientific World Journal
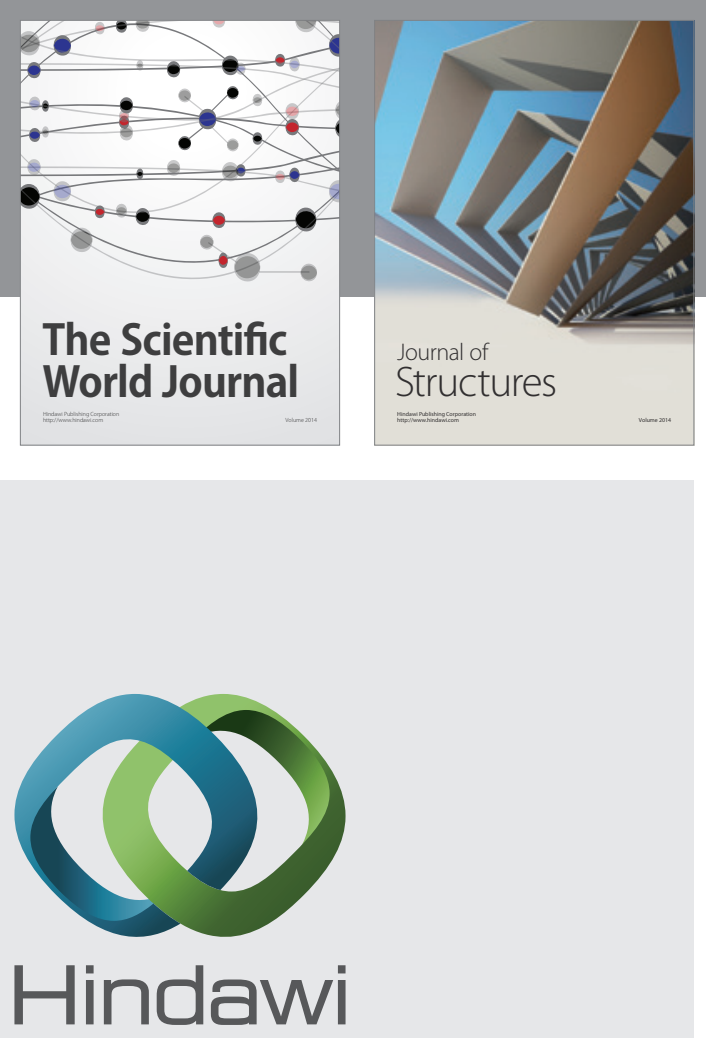

Submit your manuscripts at

http://www.hindawi.com
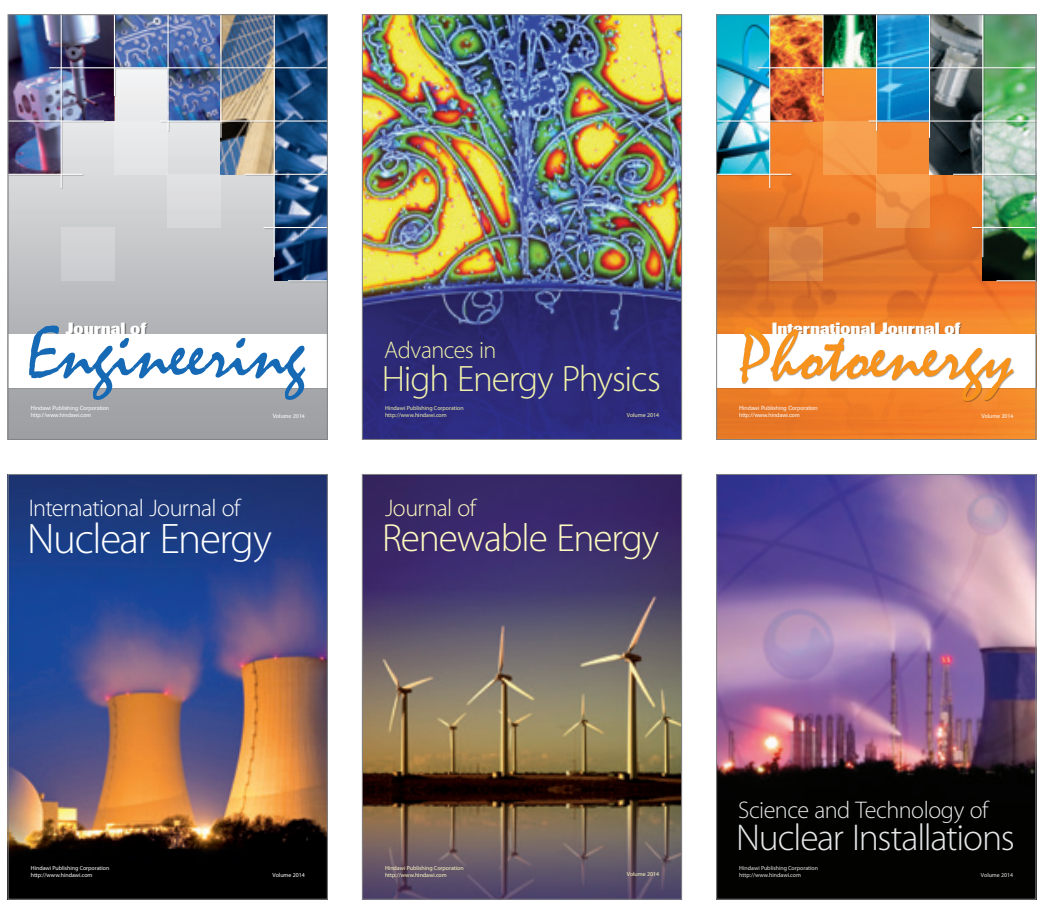
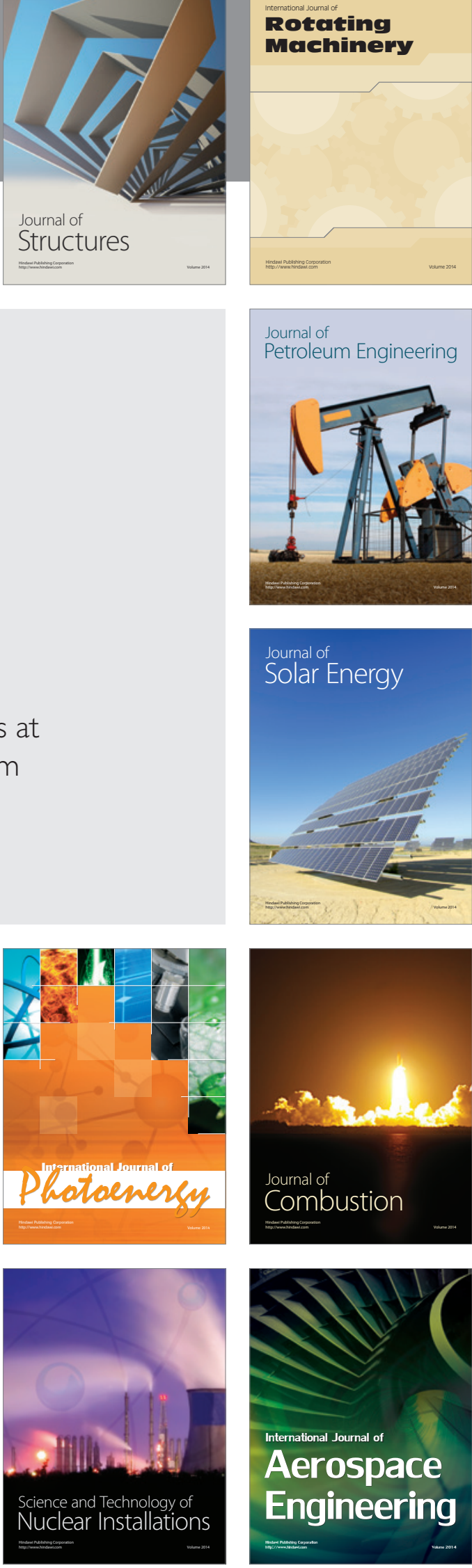